\title{
Sexual partner change and condom use among urban factory workers in northwest Tanzania
}

\author{
Martien W Borgdorff, Longin R Barongo, James N Newell, Kesheni P Senkoro, \\ Walter Devillé, Johan P Velema, R M Gabone
}

\begin{abstract}
Objective-To describe sexual partner change and condom use at the intake of a cohort study of urban factory workers in Tanzania.

Methods-From October 1991 to March 1992, 926 male and 170 female factory workers were interviewed using a structured, pre-coded questionnaire. Questionnaire reliability was assessed by pre-testing and comparison with results of unstructured interviews and carrying out repeat questionnaires on a sub-sample.

Results-Almost half of both men and women had had sexual intercourse by their 17th birthday. The period of premarital sex had an interquartile range of 2 to 10 years in men and 0 to 2.5 years in women. Having had sexual intercourse in the past month with more than one partner was reported by $22 \%$ of the men and $5 \%$ of the women. Factors associated with multiple partners in men were being born in or near Mwanza Region, having low education and low income, and being married. Condoms had been used in the past month by $3 \%$ only, mainly with casual partners. Condom use in men was associated with being young, living in town, being born in Kagera Region, high education and high income, being circumcised, and having casual or steady (non- marital) partners.

Conclusion-Information, education and communication (IEC) on sexual relationships and condom use should start at an early age, and include education at primary schools. Much sexual partner change appears to occur through steady (non-marital) partnerships, indicating the need for IEC to be expanded beyond groups such as commercial sex workers and their clients.
\end{abstract}

(Genitourin Med 1994;70:378-383)

Introduction

HIV-1 infection is more common in heterosexuals in Eastern and Southern Africa than in Europe and the U.S. ${ }^{1}$ Within these countries HIV-1 infection usually has a higher prevalence in urban than in rural areas,,$^{1-6}$ as have other sexually transmitted diseases (STDs). ${ }^{17} \mathrm{~A}$ higher rate of heterosexual partner change in more affected areas could be an important determinant of this increased prevalence. ${ }^{1}$ Extensive quantitative information on sexual partner change and condom use has recently been collected in Europe because of the HIV epidemic, ${ }^{8-10}$ but in Africa available information is still limited.

A cohort study of urban workers was initiated in a factory in Mwanza Municipality, Tanzania, in order to identify risk factors for HIV-1 seroconversion and for contracting other STDs. A second objective was to document changes in risk behaviour, in particular with respect to condom use and partner change after starting an intervention programme, and to determine whether these changes were associated with a reduced incidence of HIV-1 and other STDs.

In this paper quantitative results are reported at intake regarding sexual behaviour, in particular having multiple sexual partners and use of condoms. This intake took place from October 1991 to March 1992. The main aim of this analysis was to describe baseline information before interventions were undertaken at the factory, and to identify priorities for intervention. In a separate paper qualitative results are presented on the cultural and social background to the findings on sexual behaviour, risk perception, and behavioural change. ${ }^{11}$

\section{Methods}

Study population

The study population comprised workers at a large urban factory with a work force of 1728 workers, $13 \%$ of whom were female. All workers were invited to enrol from the start of the study. A study clinic was created at the factory in addition to an existing clinic, as the latter was too small to cope with additional activities. Prior to starting the study, the willingness of the study population to participate was determined through an anonymous, selfadministered questionnaire which produced a positive response of more than $90 \%$. The study population has been advised that the aim of the study is to determine the health status of the workers, with special interest in sexually transmitted diseases and HIV-1 infection.

Pre- and post-HIV-test counselling was offered to all. Free treatment was provided to all study participants. Condoms were distributed free of charge by all staff present at the clinic. Where necessary, patients were referred to hospital for further investigation or treatment.

Amsterdam, The

Accepted for publication 24 May 1994 


\section{Data collection techniques}

All respondents were interviewed in a private room for 30 to 45 minutes in Kiswahili by trained interviewers, using a structured and pre-coded questionnaire which was slightly different for men and women. The questionnaire covered demographic and socioeconomic variables, health and sexually transmitted diseases, sexual partners and condom use, and finally sexual techniques. For the construction of the questionnaire, use was made of information from qualitative research both within the same Region and elsewhere in Tanzania.

Through pre-testing a number of modifications were made, both in the ordering of questions and in the content. In particular questions on sexual techniques other than vaginal sexual intercourse were found to cause embarassment. Questions on oral-genital sexual contact were omitted, and questions on anal intercourse and masturbation put at the end of the questionnaire. Questions on types of sexual partners, frequency of sexual contact, and use of condoms proved to be less sensitive.

In the questionnaire a distinction was made between four types of partners: (1) spouse, (2) a partner one lives with but is not married to, (3) a steady partner one is not married to and does not live with, and (4) a casual partner. The last of these was defined by one respondent as "a strange face with whom who have sex once and then forget"11; in the questionnaire a casual partner was defined as any sexual partner not considered by respondent to be a steady partner. For further information on these different types of partners we refer to Nnko et al. ${ }^{11}$ As fewer than $1 \%$ of respondents reported having a partner in group (2), this type of partner has been considered as spouse in the analysis. Group (3) will be referred to in this paper as steady partner. After the interview respondents were physically examined, counselled, and bled for serological testing.

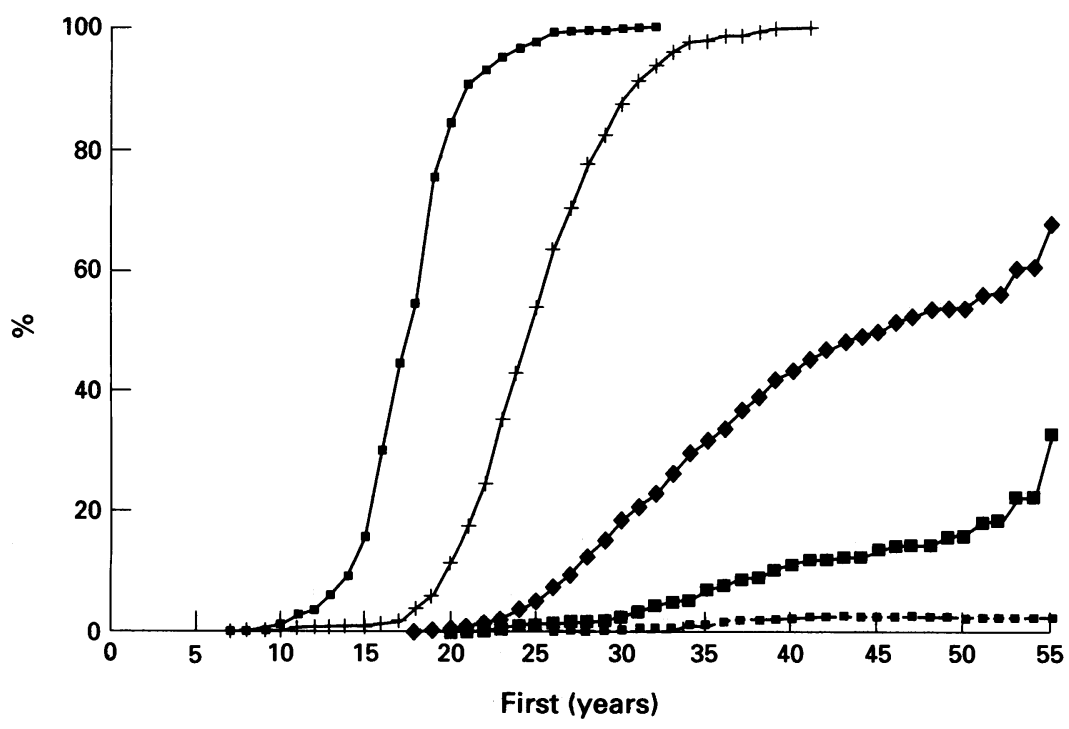

$\rightarrow$ First sex + Marriage $1 \multimap$ Marriage $2 \rightarrow$ Marriage $3 \rightarrow$ Marriage 4

Figure 1 Cumulative percentages by age of having first sexual intercourse and first, second, third, and fourth marriage in 926 male factory workers.
Data analysis

Data were analysed separately for males and females. Interquartile range (IQR) has been used as a measure of dispersion for skewed distributions. Survival analysis was used to determine the age of starting sexual intercourse, age at marriage, and the duration of marriage. Comparisons between survival curves were tested for statistical significance with the log rank test. ${ }^{12}$ Stepwise logistic regression was used to simultaneously adjust for various variables of interest. Variables were eligible for inclusion in the regression model if they were a priori thought to be of interest (for example, age) or showed an association with sexual partner change or condom use on univariate analysis. In order to assess the repeatability of responses, repeat questionnaires were administered on a subsample. In addition, a comparison was made with responses obtained from unstructured or semi-structured interviews by social scientists. For most variables a good repeatability could be demonstrated (kappa $>0 \cdot 80$ ). However, for some variables such as religion repeatability was only moderate $(0.5<$ kappa $<0.8)$, perhaps because changing churches is not uncommon. For information on casual partners repeatability was good for contacts less than a month ago, but only moderate for contacts more than a month ago.

\section{Results}

In the first 19 weeks of the study 1096 workers (926 male, 170 female) were enrolled, comprising $62 \%$ of the male and $76 \%$ of the female work force. In comparison with the data on all factory workers, study participants were more likely to be aged below 25 years (18\% vs $10 \%$ ).

\section{Age at first sexual intercourse and at first marriage}

The age distribution at first sexual intercourse is presented in fig 1 for men and fig 2 for women. By the 15 th birthday $16 \%$ of male and $6 \%$ of female respondents reported having had sexual intercourse; by the 17 th birthday these percentages were $44 \%$ and $33 \%$ respectively. By the 19 th and 21 st birthday $75 \%$ and $91 \%$ of men and women reported having had sexual intercourse respectively. Little difference was observed between men and women (log rank test $\left.\chi_{1}^{2} 1 \cdot 4, p>0.25\right)$. Secular changes in the age at first sexual intercourse were not observed.

The cumulative age distribution at first and consecutive marriages is also presented in figs 1 and 2 . By their 21 st birthdays $21 \%$ of men and $46 \%$ of women had married. Women have their first marriage at a younger age than men (log rank test $\chi_{1}{ }^{2} 17.9, \mathrm{p}<0.0001$ ). Overall, $0.2 \%$ of men and $23.5 \%$ of women in this study population had not yet married by the age of 40 years.

In those who had ever married, the median period of having had premarital sexual intercourse (that is, the difference between the age at first marriage and the age at first sexual 


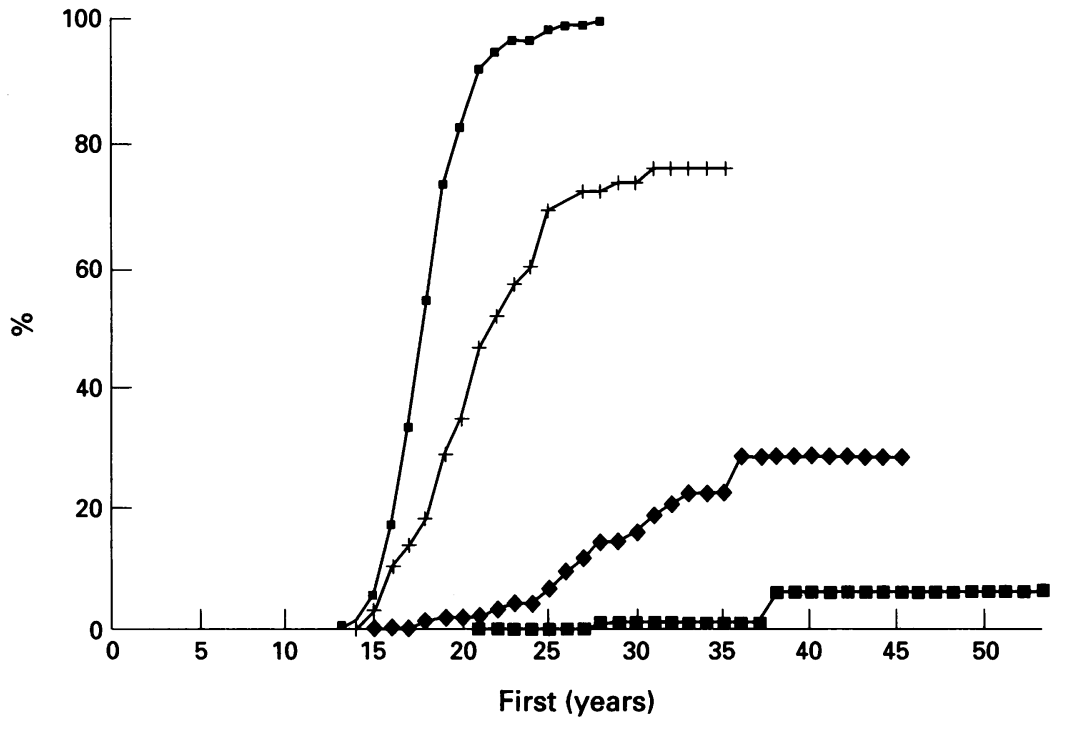

$\rightarrow$ First sex + Marriage $1 \multimap$ Marriage $2 \rightarrow$ Marriage 3

Figure 2 Cumulative percentages by age of having first sexual intercourse and first, second, and third marriage in 170 female factory workers.

intercourse) was 5 years (IQR 2 to 10 years) in men and 1 year (IQR 0 to 2.5 years) in women.

Second and third marriages were more common among men than women (figs 1 and 2 ). By their 45 th birthday $52 \%$ of men and $28 \%$ of women had married for a second time. By their 55th birthday, $33 \%$ of men and $6 \%$ of women had married for a third time. For women all second and third marriages took place after previous marriages had ended. Men had no spouse from an earlier marriage at the time of their second and third marriage in $223 / 280(80 \%)$ and $53 / 70(76 \%)$ of these marriages respectively.

\section{Stability of marriage}

The probability for a marriage to end (by divorce or death of the partner) was estimated to be $4 \%$ per year in the first 5 years of marriage, $2 \%$ over the next 5 years and $1 \%$ per year over the next 10 years. Marriage survival was slightly longer for men than for women ( $\log$ rank $\left.\chi_{1}^{2}=2.9,0.05<P<0.1\right)$. The survival curves were similar for first and second

Table 1 Distribution of having various types of partners in 926 male and 170 female urban factory workers

\begin{tabular}{|c|c|c|c|}
\hline & \multicolumn{3}{|l|}{ Number (\%) } \\
\hline & \multirow{2}{*}{$\begin{array}{l}\text { Steady partner* } \\
\text { (one or more) } \\
\text { with whom sexual } \\
\text { intercourse took } \\
\text { place in past month }\end{array}$} & \multicolumn{2}{|c|}{ Casual partnert within } \\
\hline & & past 4 weeks & past 12 months \\
\hline \multirow{3}{*}{$\begin{array}{l}\text { Males } \\
\text { Married } \\
\text { Single } \\
\text { Married but living apart, } \\
\text { separated, or widowed } \\
\text { Females }\end{array}$} & & & \\
\hline & $\begin{array}{r}147 / 724(20 \%) \\
61 / 149(41 \%)\end{array}$ & $\begin{array}{l}44 / 724(6 \%) \\
29 / 149(19 \%)\end{array}$ & $\begin{array}{r}150 / 724(21 \%) \\
81 / 149(54 \%)\end{array}$ \\
\hline & $20 / 53(38 \%)$ & $5 / 53(9 \%)$ & $22 / 53(42 \%)$ \\
\hline \multirow{2}{*}{$\begin{array}{l}\text { Married } \\
\text { Single } \\
\text { Married but living apart, } \\
\text { separated, or widowed }\end{array}$} & $\begin{array}{c}6 / 76(7 \%) \\
27 / 61(45 \%)\end{array}$ & $\begin{array}{l}0 / 76(0 \%) \\
1 / 61(2 \%)\end{array}$ & $\begin{array}{l}5 / 76(5 \%) \\
8 / 61(13 \%)\end{array}$ \\
\hline & $10 / 33(29 \%)$ & $1 / 33(3 \%)$ & $5 / 33(14 \%)$ \\
\hline
\end{tabular}

^A steady partmer is defined as a sexual partner other than a spouse one has a relationship with for some length of time.

tA casual partner is any sexual partner who is not a spouse or steady partner. marriages (log rank $\left.\chi_{1}^{2}=0 \cdot 6, P>0 \cdot 25\right)$. Five years after the wedding $18 \%$ of marriages have ended. After 10 years $27 \%$ of marriages have ended.

Marital, steady, and casual partners

At the time of interview 724/926 (78\%) of the male and $76 / 170(45 \%)$ of the female factory workers were married and living together with their spouse. Of the 724 married men 45 (6\%) had two wives, the others had one wife only. Among the married respondents $607 / 717(85 \%)$ of the men and $71 / 76(93 \%)$ of the women reported having had sex with their spouse in the past four weeks (men: median 4 times, IQR 2 to 8; women: median 5, IQR 2 to 9 ).

Having one or more (non-marital) steady partners was reported by $294 / 926(32 \%)$ of men and 75/170 (44\%) of women, and was more common among those not currently married (table 1). Among the respondents with one or more steady partners $228 / 294$ $(78 \%)$ of the men and $43 / 75(57 \%)$ of the women reported having had sex with their steady partner in the past 4 weeks (men: median 3 times, IQR 2 to 5; women: median 1 , IQR 1 to 2). The median duration of reported current steady partnerships was 7 months (IQR 4-18 months) for men and 24 months (IQR 12-36 months) for women. Men were usually older than their female steady partner. Men of all ages had steady partners, while $351 / 364(96 \%)$ of their female partners were aged less than 35 years. The male steady partners reported by women were in all age groups.

Having ever had a casual sexual partner was reported by $654 / 926(71 \%)$ of men and $63 / 170(37 \%)$ of women. $253 / 925(27 \%)$ of men and 18/170 (11\%) of women had had a casual partner within the past 12 months, again more commonly among those not currently married. Only $15 / 253(6 \%)$ of men and $1 / 18(6 \%)$ of women stated they met the casual partner in a bar. The rest were met "on the street" (men 167/253 [66\%], women 5/18 [26\%]), at a friend's house (men 24/253 [9\%], women $5 / 18[28 \%]$ ), or at a party (men $13 / 253$ [5\%], women $2 / 18$ [11\%]). Other, less frequent possibilities included wedding or burial ceremonies and discos. More information on meeting places with casual partners is given by Nnko et al. ${ }^{11}$

Determinants of having multiple partners in men Having had more than one sexual partner (including the spouse where applicable) in the past month was reported by $205 / 926(22 \%)$ of men and 8/170 (5\%) of women. Determinants of having multiple sexual partners among men are presented in table 2 . The group of women was too small for such detailed analysis.

Having more than one sexual partner was reported by $179 / 724(25 \%)$ of married men, $22 / 149(13 \%)$ of single men, and $4 / 53(8 \%)$ of those who were married but living apart, or were separated or widowed (table 2). Of the 179 married men with more than one sexual 
Table 2 Determinants for having had more than one sexual partner in the past month in 926 male urban factory workers

\begin{tabular}{|c|c|c|c|c|}
\hline Risk factor & $\begin{array}{l}\text { Number with } 2+ \\
\text { sexual partners/ } \\
\text { Nr seen }(\%)\end{array}$ & $\chi^{2}+t e s t$ & $\begin{array}{l}\text { Odds ratio } \\
\text { (95\% CI) Crude }\end{array}$ & $\begin{array}{l}\text { Adjusted for } \\
\text { significant } \\
\text { factors* }\end{array}$ \\
\hline \multicolumn{5}{|l|}{ Age (year) } \\
\hline $15-24$ & $25 / 146(17)$ & $p>0.05$ & 1 & 1 \\
\hline $25-34$ & $77 / 297(26)$ & & $1 \cdot 7(1 \cdot 0-2 \cdot 8)$ & $1 \cdot 3(0 \cdot 7-2 \cdot 6)$ \\
\hline $35-44$ & $75 / 350(21)$ & & $1 \cdot 3(0 \cdot 8-2 \cdot 2)$ & $0.4(0.2-0.9)$ \\
\hline \multirow{2}{*}{\multicolumn{5}{|c|}{ Residence }} \\
\hline & & & & \\
\hline Mwanza Municipality & $175 / 826(21)$ & $p>0.05$ & 1 & 1 \\
\hline Outside Municipality & $28 / 94(30)$ & & $1.6(1 \cdot 0-2 \cdot 5)$ & $1 \cdot 1(0 \cdot 6-1 \cdot 7)$ \\
\hline \multicolumn{5}{|l|}{ Birth place } \\
\hline Mwanza Region & $153 / 557(27)$ & $\mathrm{p}<0.001$ & 1 & 1 \\
\hline Shinyanga/Mara & $37 / 164(23)$ & & $0 \cdot 8(0 \cdot 5-1 \cdot 2)$ & $0 \cdot 7(0 \cdot 5-1 \cdot 1)$ \\
\hline Kagera & $3 / 39(8)$ & & $0.2(0.1-0.7)$ & $0.4(0 \cdot 1-1 \cdot 2)$ \\
\hline Other & $12 / 166(7)$ & & $0.2(0.1-0.4)$ & $0.2(0 \cdot 1-0.5)$ \\
\hline \multicolumn{5}{|l|}{ Marital status } \\
\hline Married & $179 / 724(25)$ & $\mathrm{p}<0.001$ & 1 & 1 \\
\hline Never married & $22 / 149(15)$ & & $0.5(0.3-0.9)$ & $0 \cdot 6(0 \cdot 3-1 \cdot 3)$ \\
\hline Married but living apart, separated, or widowed & $4 / 53(8)$ & & $0.2(0 \cdot 1-0 \cdot 7)$ & $0.3(0 \cdot 1-0.8)$ \\
\hline \multicolumn{5}{|l|}{ Education } \\
\hline$<5$ yr primary & $24 / 88(27)$ & $\mathrm{p}=(0.01)$ & $1 \cdot 2(0 \cdot 7-2 \cdot 0)$ & $1 \cdot 1(0 \cdot 6-1 \cdot 8)$ \\
\hline 5-7 yr primary & $168 / 717(23)$ & trend: & & \\
\hline secondary education & $13 / 121(11)$ & $\mathrm{p}<0.01$ & $0.4(0 \cdot 2-0 \cdot 7)$ & $0.5(0 \cdot 3-1 \cdot 0)$ \\
\hline \multicolumn{5}{|l|}{ Income per capita† } \\
\hline$<1500$ & $57 / 186(31)$ & $\mathrm{p}<0.001$ & 1 & 1 \\
\hline $1500-$ & $43 / 176(24)$ & trend: & $0 \cdot 7(0 \cdot 5-1 \cdot 2)$ & $0 \cdot 7(0 \cdot 4-1 \cdot 2)$ \\
\hline $2000-$ & $43 / 168(26)$ & $\mathrm{p}<0.001$ & $0.8(0 \cdot 5-1 \cdot 2)$ & $0.8(0.5-1.4)$ \\
\hline $2500-$ & $31 / 152(20)$ & & $0 \cdot 6(0 \cdot 4-1 \cdot 0)$ & $0.7(0.4-1 \cdot 2)$ \\
\hline $3500-$ & $30 / 239(13)$ & & $0.3(0.2-0.5)$ & $0.5(0.3-0.8)$ \\
\hline
\end{tabular}

*Factors adjusted for in logistic regression were age, birthplace, marital status, education, and income per capita. $\dagger$ (monthly household income in Tanzania shilling)/(number of adults $+1 / 2$ number of children).

partner only $33(18 \%)$ had had sex with more than one spouse; the other $82 \%$ had had extramarital relationships. Factors associated with having had multiple sexual partners in the past month (after adjusting for the other significant variables in logistic regression) were: being born in Mwanza or the neighbouring Mara or Shinyanga Regions, having had less education or having a low income, and being married. Having had more than one

Table 3 Condom use ever and condom use last month by risk factor in 926 male urban factory workers

\begin{tabular}{|c|c|c|c|c|c|c|}
\hline \multirow[b]{2}{*}{ Risk factor } & \multicolumn{3}{|l|}{ Condom use ever } & \multicolumn{3}{|c|}{ Condom use last month } \\
\hline & $\begin{array}{l}\text { Nr using/ } \\
\text { Total (\%) }\end{array}$ & $\begin{array}{l}\text { Crude OR } \\
\text { (p-value) }\end{array}$ & $\begin{array}{l}\text { OR (95\% CI) } \\
\text { adjusted for } \\
\text { significant factors* }\end{array}$ & Nr using/Total (\%) & Crude OR & $\begin{array}{l}\text { OR (95\% CI) } \\
\text { adjusted for } \\
\text { significant factorst }\end{array}$ \\
\hline \multicolumn{7}{|l|}{ Age (years) } \\
\hline $\begin{array}{l}15-24 \\
25-34\end{array}$ & $\begin{array}{l}46 / 145(32) \\
48 / 297(16)\end{array}$ & $1(\mathrm{p}<0.001)$ & $1.5(0.2-0.0) 7$ & $9 / 145(6)$ & $1(\mathrm{p}<0.05)$ & \\
\hline $\begin{array}{l}25-34 \\
35-44\end{array}$ & $40 / 349(11)$ & & $\left.\begin{array}{l}0.5(0.3-0.9) \\
0.4(0.3-0.8)\end{array}\right\}$ & 9/296 (3) & 0.5 & \\
\hline $45+$ & $7 / 133(5)$ & & $0.3(0 \cdot 1-0.7)\}$ & $10 / 483(2)$ & $0 \cdot 3$ & \\
\hline \multicolumn{7}{|l|}{ Residence } \\
\hline Municipality & $135 / 824(16)$ & $1(p>0.05)$ & 1 & $27 / 824(3)$ & $1(p>0.05)$ & \\
\hline \multicolumn{7}{|l|}{ Having had sex with casual partner } \\
\hline $\begin{array}{l}\text { Past month } \\
\text { Pant past }\end{array}$ & $25 / 78(32)$ & $3 \cdot 8$ & $3.5(1.9-6.4)$ & $11 / 77(14)$ & $13 \cdot 4$ & $13 \cdot 1(4 \cdot 8-35 \cdot 8)$ \\
\hline $1-4$ months & $34 / 111(31)$ & & $3.2(1.9-5.4)$ & $7 / 111(6)$ & $5 \cdot 5$ & $5 \cdot 7(1.9-17 \cdot 0)$ \\
\hline$>4$ months ago or never & $81 / 734(11)$ & $1(\mathrm{p}<0.001)$ & & 9/735 (1) & $1(p<0.001)$ & \\
\hline \multicolumn{7}{|c|}{ Having had sex with steady partner past month } \\
\hline 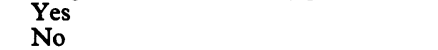 & $\begin{array}{l}49 / 227(22) \\
92 / 697(13)\end{array}$ & 1.8 & $2 \cdot 1(1 \cdot 3-3 \cdot 3)$ & $\begin{array}{l}15 / 227(7) \\
13 / 697(2)\end{array}$ & 3.7 & $5 \cdot 9(2 \cdot 4-14 \cdot 6)$ \\
\hline \multicolumn{7}{|l|}{ Education } \\
\hline$<5$ year & $2 / 87(2)$ & $0 \cdot 2$ & $0 \cdot 2(0 \cdot 0-1 \cdot 2)\}$ & $18 / 803(2)$ & $1(p<0.001)$ & 1 \\
\hline $\begin{array}{l}\text { S-7 year } \\
\text { secondary }\end{array}$ & $\begin{array}{l}90 / 10(13) \\
43 / 121(36)\end{array}$ & 3.6 (trend: $\mathrm{p}<0.001$ ) & $3.5(2 \cdot 2-5 \cdot 8)$ & $10 / 121(8)$ & 3.9 (trend: $p<0.01$ ) & $4 \cdot 4(1 \cdot 8-10 \cdot 8)$ \\
\hline \multicolumn{7}{|l|}{ Income per capita† } \\
\hline $\begin{array}{l}<1500 \\
1500-\end{array}$ & $\begin{array}{l}19 / 185(10) \\
14 / 176(8)\end{array}$ & $\begin{array}{l}1(\mathrm{p}<0.001) \\
0.8\end{array}$ & $\begin{array}{l}1 \\
0.9 \\
(0.4-2.0)\end{array}$ & $\begin{array}{l}5 / 186(3) \\
2 / 175(1)\end{array}$ & $\begin{array}{l}1(p>0.05) \\
0.4\end{array}$ & \\
\hline $2000-$ & $16 / 168(10)$ & & $1.0(0.5-2 \cdot 2)$ & $4 / 168(2)$ & 0.9 & \\
\hline $2500-$ & $29 / 151$ (19) & $2 \cdot 1$ & $2 \cdot 1(1 \cdot 1-4 \cdot 3)$ & $6 / 151(4)$ & 1.5 & \\
\hline $3500-$ & $61 / 239(26)$ & 3.0 (trend: $p<0.001$ ) & $1.8(1.0-3.5)$ & $11 / 239(5)$ & $1 \cdot 7$ & \\
\hline \multicolumn{7}{|c|}{ 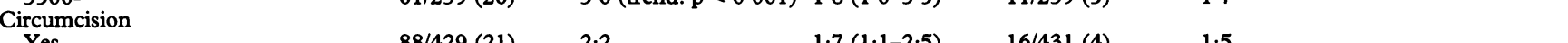 } \\
\hline $\begin{array}{l}\text { Yes } \\
\text { No }\end{array}$ & $\begin{array}{l}88 / 429(21) \\
53 / 495(11)\end{array}$ & $\begin{array}{l}2.2 \\
1(p<0.001)\end{array}$ & $1 \cdot 7(1 \cdot 1-2 \cdot 5)$ & $\begin{array}{l}16 / 431(4) \\
12 / 493(2)\end{array}$ & $\begin{array}{l}1.5 \\
1(p>0.05)\end{array}$ & \\
\hline \multicolumn{7}{|l|}{ Genital discharge last } \\
\hline $\begin{array}{l}\text { Never } \\
4 \text { months }+ \\
<4 \text { months/now }\end{array}$ & $\begin{array}{l}67 / 509(13) \\
57 / 364(16) \\
17 / 51(33)\end{array}$ & $\begin{array}{l}1(p<0.01) \\
1.2 \\
3.3\end{array}$ & & $\begin{array}{l}14 / 510(3) \\
9 / 363(2) \\
5 / 51(10)\end{array}$ & $\begin{array}{l}1(\mathrm{p}<0.05) \\
0.9 \\
3.9\end{array}$ & $\begin{array}{l}1 \\
0 \cdot 5(0 \cdot 2-1 \cdot 4) \\
3 \cdot 7(1 \cdot 1-12 \cdot 2)\end{array}$ \\
\hline & & (trend: $\mathrm{p}<0.001$ ) & & (trend: $\mathrm{p}<0.05$ ) & & \\
\hline \multicolumn{7}{|l|}{ Birth place } \\
\hline Shinyanga/Mara & $31 / 164(19)$ & $\begin{array}{l}1 .(p=0.001) \\
1.7\end{array}$ & & $\begin{array}{l}13 / 156(2) \\
5 / 163(3)\end{array}$ & $1.3<0.01)$ & $1 \cdot 1(0 \cdot 3-3 \cdot 5)$ \\
\hline Kagera & $12 / 39(31)$ & $3 \cdot 5$ & & $5 / 39$ (13) & $6 \cdot 1$ & $6 \cdot 7(1 \cdot 7-25 \cdot 6)$ \\
\hline Other & $36 / 165(22)$ & $2 \cdot 2$ & & $5 / 166(3)$ & $1 \cdot 3$ & $1.6(0.5-5 \cdot 3)$ \\
\hline \multirow{4}{*}{$\begin{array}{l}\text { Marital status } \\
\text { Married } \\
\text { Single } \\
\text { Married but living apart, separated, } \\
\text { or widowed }\end{array}$} & & & & & & \\
\hline & $85 / 723(12)$ & $1(p<0.01)$ & & $14 / 722(2)$ & $1(\mathrm{p}<0.005)$ & \\
\hline & & & & & & \\
\hline & $7 / 53$ (13) & $1 \cdot 1$ & & $3 / 53(6)$ & $3 \cdot 0$ & \\
\hline
\end{tabular}

*Significant factors adjusted for in logistic regression were age, residence, education, income, circumcision, having had sex with a steady partner, and having had sex with a casual partner.

†Significant factors adjusted for in logistic regression were birthplace, education, having had sex with a steady partner, and having had sex with a casual partner. $\neq$ (monthly household income in Tanzania shilling)/(number of adults $+1 / 2$ number of children). 
sexual partner in the past month was also associated with having ever had a genital discharge. This was not included in the regression model as it was thought to be a consequence rather than a determinant of sexual partner change.

Determinants of condom use in men

Overall, 141/924 (15\%) of men and 30/170 $(18 \%)$ of women had ever used a condom. Only $28 / 924(3 \%)$ of men and $5 / 170(3 \%)$ of women had used a condom in the past month. A number of determinants of condom use in men were identified (table 3 ). The group of women was too small for this analysis.

Factors associated with condom use in men after adjusting for the other significant variables in logistic regression were being in the younger age groups, living within the municipality, having had sexual intercourse with a casual or steady partner, having a higher level of education, having a higher income, having had a recent genital discharge, being circumcised, and being born in Kagera (a neighbouring Region with a high prevalence of HIV-1 infection). Condoms were used most frequently with casual partners $(18 \%$ of sexual contacts), much less with steady partners $(2 \%)$, and hardly with spouses $(0 \cdot 2 \%)$.

Neither sexual partner change, nor condom use was found to be associated with the religion of respondents.

\section{Discussion}

This study shows that high risk behaviour in this group of factory workers was widespread, in particular among men; $22 \%$ of male workers reported having had more than one sexual partner in the past month, $97 \%$ had not used a condom at all in the past month, and $85 \%$ reported they had never used them in their life.

It is difficult to assess the validity of selfreported sexual behaviour. Age at first sexual intercourse may have been misreported due to recall bias, or because of a tendency to give socially desirable answers. The direction of the latter bias is likely to have been towards higher ages at first sexual intercourse, in particular among women. If this bias has occurred, the period of premarital sexual intercourse will have been underestimated.

During pre-testing, people reported to be at ease answering questions on partner relations (but not questions on sexual techniques). Having had multiple partners in the past month was reported by a large proportion of men $(22 \%)$, but less so by women (5\%). In men it was associated with having a genital discharge or genital ulcer at physical examination (unpublished data), suggesting that this high risk behaviour is reported with some accuracy. As women are not socially expected to have many sexual partners, in particular not when they are married, this may have biased (that is, reduced) the number of sexual partners reported by women.

Further validation studies are needed. Validation of self-reported sexual behaviour has been attempted in various studies aiming at quantifying risk behaviour for STDs and HIV, with encouraging results. ${ }^{13-18}$ However, very few such studies appear to have been carried out in Africa, and much more work on this issue is needed. ${ }^{19}$

A limitation of the study is self-selection bias, as $\mathbf{3 7 \%}$ of workers had not (yet) enrolled at the time of this analysis. The direction of this analysis is uncertain: those declining to participate might have had increased risk behaviour (and be afraid to be tested for HIV1 and other sexually transmitted diseases) or reduced risk behaviour (and have less interest in being tested for sexually transmitted diseases).

Age at first sexual intercourse in this study is similar to that reported from other countries in Africa, ${ }^{20-22}$ Haiti, ${ }^{23}$ and Europe, ${ }^{81024}$ starting in the mid-teens in both sexes, and with a period of premarital sexual intercourse of several years in most men and a substantial proportion of women. Contrary to findings in Europe, ${ }^{9}$ no evidence was found for a shift over time towards younger ages for first sexual intercourse. IEC on sexual relationships and condom use should therefore start before the mid-teens and preferably include education at primary schools.

Rates of acquisition of marital partners and marital breakdown appear to be small in comparison with the rates of acquisition and breakdown of steady and casual partnerships. Polygamy only plays a minor role in sexual partner change in this population. Follow-up is expected to provide more information on the relative contribution of marital partner change to overall partner change. Female factory workers were less likely to get married, and after marriage were more likely to divorce than male workers. Female factory workers appear to be a special group, and are probably not representative for the general female population.

Although extramarital relationships were reported much more commonly than for instance in the U.K., ${ }^{8}$ similar rates of having extramarital sexual partners have been reported from Uganda, ${ }^{25}$ Zaire, ${ }^{20}{ }^{26}$ Zimbabwe, ${ }^{27}$ Ghana, ${ }^{21}$ and other countries in Africa. ${ }^{22}$

Many more men had sexual intercourse in the past month with steady than with casual partners (although over the past year these proportions did not differ). As relationships with steady partners usually last less than two years, steady partnerships may contribute substantially to the overall rate of sexual partner change and therefore to the risk of acquiring HIV or other sexually transmitted diseases. This implies that condom promotion needs to be expanded beyond groups such as commercial sex workers and their clients.

No association was found between age group and having multiple partners, contrary to findings in Europe, where having multiple partners was more frequently reported by young adults. ${ }^{910}$ However, the types of partner vary with age, casual and steady partners becoming less common and spouses more 
common with increasing age (data not shown). Having had multiple partners in the past month was more often reported by men with less education and a low income. This is in contrast to previous reports from African countries, ${ }^{22}$ where a higher level of education was associated with more often having had casual partners in the past 12 months. Perhaps behaviour has changed in those with more education, although response bias can not easily be ruled out: respondents with more education might have been more receptive to health education and have answered questions accordingly, without necessarily having changed behaviour. HIV-1 infection was not associated with level of education or income (data not shown). This is consistent with a higher risk in the past and a lower risk at present for better educated men.

Only $3 \%$ of male and female respondents had used a condom in the past month. Condoms were used mostly with casual partners, much less with steady partners, and least of all with spouses. However, even with casual partners, condoms protected only $18 \%$ of the sexual contacts which took place in the past month. This low use of condoms was not unexpected. ${ }^{6}{ }^{28} 29$ However, the data suggest that condom use has increased recently: condoms were used more by the young, better educated, and those having been born in high risk Regions. The increased condom use by the young and better educated has also been described in The Gambia. ${ }^{30}$ The increased condom use in those with higher incomes may have been partly due to fewer economic barriers to condom use for this group. Unfortunately, groups with low education and income were not only more likely to report having had multiple sexual partners, but also less likely to report having used condoms. This group should be a priority for intervention.

We thank the Principal Secretary, Ministry of Health and the Director General, National Institute for Medical Research for permission to carry out the study and to publish its results.

We thank Dr G Lwihula and Prof R A Coutinho for support in developing the questionnaires and Prof A S Muller, and Dr C M Varkevisser for critically reviewing the manuscript.

The research for this publication was financed by the The research for this publication was financed by the
Netherlands' Minister for Development Cooperation, Section Netherlands' Minister for Development Cooperation, Section for Research and Technology, P O Box 20061, 2500 EB, The
Hague, as part of the Tanzania-Netherlands Research Project Hague, as part of the Tanzania-Netherlands Research Project on AIDS and HIV Infection in Mwanza Region. Responsibility for the contents and for the opinions expressed
rests solely with the authors; publication does not constitute an rests solely with the authors; publication does not constitute an Co-operation.

The research for this publication was financed by the Netherlands' Minister for Development Cooperation, Section for Research and Technology, P O Box 20061, 2500 EB, The Hague, as part of the Tanzania-Netherlands Research Project on AIDS and HIV Infection in Mwanza Region.

1 Piot $\mathrm{P}$, Laga $M$, Ryder R, et al. The global epidemiology of HIV infection: continuity, heterogeneity, and change. f AIDS 1990;3:403-12.

2 Piot P, Plummer FA, Mhalu FS, Lamboray JL, Chin J, Mann JM. AIDS: an international perspective. Science 1988;239:573-9.

3 Rwandan HIV seroprevalence study group. Nationwide community-based serological survey of HIV-1 and other human retrovirus infections in a Central African country. Lancet 1989;i:941-3.

4 Killewo J, Nyamuryekung'e K, Sandström A, et al. Prevalence of HIV-1 infection in the Kagera region of Tanzania: a population-based study. AIDS 1990;4 1081-5.

5 Serwadda D, Wawer MJ, Musgrave SD, Sewankambo NK, Kaplan JE, Gray RH. HIV risk factors in three geographic strata of rural Rakai District, Uganda. AIDS 1992;6:983-9.

6 Barongo LR, Borgdorff MW, Mosha FF, et al. The epidemiology of HIV-1 infection in urban areas, roadside settlements and rural villages in Mwanza Region, settlements and rural villages
Tanzania. AIDS 1992;6:1521-8.

7 Laga M, Nzila N, Goeman J. The interrelationship of sexually transmitted diseases and HIV infection: implications for the control of both epidemics in Africa. AIDS 1991;5(suppl 1):S55-S63.

8 Johnson AM, Wadsworth J, Elliott P, et al. A pilot study of sexual lifestyle in a random sample of the population of Great Britain. AIDS 1989;3:135-41.

9 Johnson AM, Wadsworth J, Wellings K, Bradshaw S, Field Sexual lifestyles and HIV risk. Nature 1992;360: $410-2$.

10 ACSF investigators. AIDS and sexual behaviour in France. Nature 1992;360:407-9.

11 Nnko S, Mwanga J, Varkevisser C, et al. Risk perception and behavioural change in relation to AIDS-An exploratory study among factory workers in Mwanza exploratory study among factory workers in Mwanza town, Tanzania. In: Dantzenberg M, Nnko S, Chiduo $\mathrm{B}$, et al. Action Research for the Development of
Interventions to Reduce HIV Transmissions in Mwanza Interventions to Reduce HIV Transmissions in Mwan

12 Armitage P, Berry G. Statistical Methods in Medical Research. 2nd Ed. Oxford: Blackwell Scientific Publications, 1987:429-33.

$13 \mathrm{McQueen} \mathrm{D}$. Understanding sexual behaviour. AIDS 1992;6:329-30

14 Coates RA, Calzavara LM, Soskolne CL, et al. Validity of sexual histories in a prospective study of male sexual contacts of men with AIDS or an AIDS related concontacts of men with Alt

15 James NJ, Bignell CJ, Gillies PA. The reliability of selfreported sexual behaviour. AIDS 1991;5:333-6.

16 Upchurch DM, Weisman CS, Shepherd M, et al. Interpartner reliability of reporting of recent sexual behaviors. Am ₹ Epidemiol 1991;134:1159-66.

17 Seage GR, Mayer KH, Horsburgh CR, Cai B, Lamb GA Corroboration of sexual histories among male homosexual couples. Am $\mathcal{F}$ Epidemiol 1992;135:79-84.

18 Wilson D, Chiroro P, Lavelle S, Mutero C. Sex workers, client sex behaviour and condom use in Harare, Zimbabwe. AIDS Care 1989;1:269-80.

19 Pickering $\mathrm{H}$. Asking questions on sexual behaviour. testing methods from the social sciences. Health $\mathrm{Pol}$ Plann 1988;3:237-44.

20 Bertrand JT, Makani B, Hassig SE, et al. AIDS-related knowledge, sexual behaviour, and condom use among men and women in Kinshasa, Zaire. Am f Public Health 1991;81:53-8.

21 Neequaye AR, Neequaye JE, Biggar RJ. Factors that could influence the spread of AIDS in Ghana, West Africa: knowledge of AIDS, sexual behavior, prostitution, and traditional medical practices. F Acq Imm Def Syndr 1991;4:914-9.

22 Carael M, Cleland J, Adeokun L, and Collaborating Investigators. Overview and selected findings of sexual behaviour surveys. AIDS 1991;5(Suppl):S65-S75

23 Halsey NA, Coberly JS, Holt E, et al. Sexual behaviour smoking, and HIV-1 infection in Haitian women. $f A M A$ 1992;267:2062-6.

24 Forman D, Chivers C. Sexual behaviour of young and middle aged men in England and Wales. BMF 1989; 298:1137-42.

25 Müller O, Barugahare L, Schwartländer B, et al. HIV prevalence, attitudes and behaviour in clients of a confidential HIV testing and counselling centre in Uganda. AIDS 1992;6:869-74

26 Ryder RW, Ndilu M, Hassig SE, et al. Heterosexual transmission of HIV-1 among employees and their spouses at two large businesses in Zaire. AIDS 1990;4:725-32.

27 Bassett MT, Latif AS, Katzenstein DA, Emmanuel JC. Sexual behaviour and risk factors for HIV infection in a group of male factory workers who donated blood in group of male factory workers who donated blood in

28 Goldberg HI, Lee NC, Oberie MW, Peterson HB. Knowledge about condoms and their use in less developed countries during a period of rising AIDS prevalence. Bull Wrld Hlth Org 1989;67:85-91.

29 Forster SJ, Furley KE. 1988 public awareness survey on AIDS and condoms in Uganda. AIDS 1989;3:147-54.

30 Wilkins HA, Alonso P, Baldeh S, et al. Knowledge of AIDS, use of condoms and results of counselling subjects with asymptomatic HIV2 infection in The Gambia. AIDS Care 1989;1:247-56. 